\title{
PRODUTIVIDADE E QUALIDADE DO MELÃO CANTALOUPE, CULTIVADO EM AMBIENTE PROTEGIDO, VARIANDO O NÚMERO E A POSIÇÃO DOS FRUTOS NA PLANTA $\left({ }^{1}\right)$
}

\author{
ROBERTO CLEITON FERNANDES DE QUEIROGA $\left(^{(*}\right)$; MÁRIO PUIATTI $\left({ }^{2}\right)$; \\ PAULO CEZAR REZENDE FONTES $\left({ }^{2}\right)$; PAULO ROBERTO CECON $\left({ }^{3}\right)$
}

\begin{abstract}
RESUMO
Os frutos do meloeiro são considerados fortes drenos que alteram a distribuição de fotoassimilados entre os órgãos da planta. Objetivou-se nesse trabalho determinar a produção e a qualidade de frutos de meloeiro em ambiente protegido em função do número e da posição de fixação dos frutos na planta. $\mathrm{O}$ experimento foi desenvolvido em fatorial $2 \times 2$ em blocos ao acaso, com cinco repetições, provenientes da combinação de número de frutos por planta ( 1 e 2 ) e posição de fixação dos frutos na planta (entre $5 .^{\circ}$ e $8 .^{\circ}$ nós e entre $15 .^{\circ}$ e $18 .^{\circ}$ nós). O melão cultivar 'Torreon', do grupo Cantalupensis, foi plantado em vasos de $11,5 \mathrm{dm}^{3}$ contendo como substrato apenas fibra de coco adubada com macro e micronutrientes. Comparado a plantas com dois frutos, nas plantas com apenas um fruto ocorreram os maiores valores de: massa dos frutos (MF), reticulação da casca (RC), comprimento, índice de formato, espessura da polpa, índice de maturação (IM), sólidos solúveis (SS), açúcares solúveis totais, açúcares não redutores. Em plantas com apenas um fruto, ocorreu redução na produtividade comercial (PC) de $21,4 \%$ em frutos fixados especificamente entre o $5 .^{\circ}$ e $8 .^{\circ}$ nós e $24,9 \%$ em frutos do $15 .^{\circ}$ e $18 .^{\circ}$ nós comparada a plantas com dois frutos. Em frutos fixados na posição do $15 .^{\circ}$ e $18 .^{\circ}$ nós ocorreram maiores MF, IM, PC e ciclo da cultura, bem como, menores RC e acidez total titulável. Foram obtidas correlações significativas para área foliar por fruto (AF) x MF de 0,81, AF x SS de 0,79, MF x SS de 0,68, MF x RC de 0,72 e RC x SS de 0,51.
\end{abstract}

Palavras-chave: Cucumis melo L., manejo da planta, relação fonte-dreno e pós-colheita.

\author{
ABSTRACT \\ FRUIT YIELD AND QUALITY OF CANTALOUPE MELON, UNDER GREENHOUSE \\ CONDITIONS, AS AFFECTED BY NUMBER OF FRUITS AND POSITION IN THE PLANT
}

Muskmelon fruits are strong sink affecting assimilate distribution among the plant organs. This experiment aimed at to determine yield and quality of 'Torreon' cultivar in greenhouse conditions as affected by fruit number and position in the plant. A $2 \times 2$ factorial was set in randomized block design, with five replications. Treatments combined fruit number per plant (1 and 2) and position in the vine (among $5^{\text {th }}-8^{\text {th }}$ node and among $15^{\text {th }}-18^{\text {th }}$ node), planted in $11,5 \mathrm{dm} 3$ pot with coconut fiber fertilized with macro and micronutrients. Compared to plants with two fruits, in plants with only one fruit there were the highest values of fruits mass (MF), netted rind (RC), fruit length, format index, flesh thickness, maturation index (IM), soluble solids (SS), total soluble sugars and no reducing sugars. Compared to plants with two fruits in plants with one fruit there was a reduction in the commercial productivity (PC) of $21.4 \%$ in fruits between $5^{\text {th }}$ and $8^{\text {th }}$ nodes had $24.9 \%$ in fruits of $15^{\text {th }}$ and $18^{\text {th }}$ nodes. Fruits of the $15^{\text {th }}$ and $18^{\text {th }}$ nodes presented higher MF, IM, PC and culture cycle, as well as lower RC and total titratable acidity. Positive and significant correlations were obtained for leaf area per fruit (AF) $\mathrm{x}$ MF of $0.81, \mathrm{AF} \times$ SS of $0.79, \mathrm{MF} \times \mathrm{SS}$ of $0.68, \mathrm{MF} \times \mathrm{RC}$ of 0.72 and RC $\times$ SS of 0.51.

Key words: Cucumis melo L., plant management, sink-source and post-harvest.

$\left({ }^{1}\right)$ Recebido para publicação em 4 de maio de 2007 e aceito em 9 de maio de 2008.

$\left({ }^{2 ; 3}\right)$ Departamentos de Fitotecnia e Informática, Universidade Federal de Viçosa - UFV, 36571-000 Viçosa (MG). Email: robertocleiton@hotmail.com $(*)$ Autor correspondente. 


\section{INTRODUÇÃO}

O meloeiro é uma olerácea tropical cultivada em diversos países do mundo. No Brasil, em 2006, a produção foi de 500 mil toneladas em 21.350 ha de área cultivada (IBGE, 2007), gerando divisas e emprego de mão-de-obra nas regiões produtoras. $\mathrm{O}$ Nordeste, com cultivo a céu aberto, é responsável por mais de $90 \%$ da produção brasileira, todavia, nos últimos anos, tem havido grande expansão do cultivo dos melões em ambiente protegido, especialmente os nobres (Cucumis melo L. grupo Cantalupensis), no Centro-Sul do Brasil, gerando demanda de informações técnicas sobre o manejo e comportamento da cultura nesse sistema de cultivo.

Em razão da exigência da cultura em temperaturas elevadas, a produção de melão na Região Sudeste do Brasil só é possível em cultivo no período de primavera/ verão. No entanto, nessa região, sobretudo o verão, caracteriza-se por precipitações pluviais elevadas e freqüentes, as quais dificultam os tratos culturais, tais como, manejo de plantas daninhas e aplicação de defensivos, favorecendo a incidência de doenças e ataque de pragas que causam desfolha das plantas, resultando em queda de produtividade e qualidade dos frutos (CoELHo et al., 2003). O cultivo em ambiente protegido constitui-se em estratégia para contornar esses problemas. Todavia, em razão do elevado custo do espaço, as plantas devem ser conduzidas na vertical, o que exige tutoramento e podas. As podas visam promover o equilíbrio no particionamento de assimilados entre órgãos vegetativo e reprodutivo e podem ser realizadas por meio do manejo das ramificações e ou dos frutos, seja pelo raleio seja pelo controle da posição da sua fixação na planta.

A competição por assimilados entre drenos afeta a taxa de crescimento da planta e a fixação dos frutos em muitas espécies. O rendimento da cultura do meloeiro em ambiente protegido responde a alterações na relação entre fonte e dreno. Nessa espécie, a remoção de frutos permite à planta direcionar os fotossintatos disponíveis para os frutos remanescentes ou para o crescimento vegetativo (VALANTin et al., 1998). Com isso, a remoção de drenos competitivos leva à maior fixação de frutos subseqüentes em razão de a maior área foliar disponível por fruto permitir maior aporte de assimilados para o fruto durante a divisão e expansão celular e, próximo à colheita permitir o acúmulo de açúcares (LoNG et al., 2004). Todavia, a competição por assimilados por meio do aumento de frutos fixados pode levar à diminuição da massa e do teor de sólidos solúveis em melões Cantaloupe (COSTA et al., 2004; VALANTIN-MORINSON et al., 2006).
Em meloeiro, a posição de saída do ramo produtivo pode influenciar tanto a produtividade quanto a qualidade dos frutos produzidos. MARUYAMA et al. (2000), observaram que a posição do fruto não influenciou sua massa, o número médio de frutos por planta e o teor de sólidos solúveis quando eles foram conduzidos em ramos entre o $5 .^{\circ}$ e $8 .^{\circ}$ nós, $9 .^{\circ}$ e $11 .^{\circ}$ nós e $12 .^{\circ}$ e $15 .^{\circ}$ nós; entretanto, obtiveram menor produção total por planta quando os frutos se fixaram entre o $5 .^{\circ} \mathrm{e}$ $8 .^{\circ}$ nós. Também no meloeiro, SYN et al. (1991) observaram que houve diferença para a posição de fixação dos frutos com maior teor de sólidos solúveis obtido em frutos fixados entre o $8 .^{\circ}$ e $10 .^{\circ}$ nós, comparado àqueles fixados entre o $4 .^{\circ}$ e o $6 .^{\circ}$ nós e entre $6 .^{\circ}$ e $8 .^{\circ}$ nós. Por outro lado, em melancia, SeAbra Júnior et al. (2003) observaram maior teor de sólidos solúveis em frutos fixados entre o $8 .^{\circ}$ e $11 .^{\circ}$ nós, quando comparado aos frutos fixados entre o $13 .^{\circ}$ e $16 .^{\circ}$ nós sem, no entanto, ter havido efeito na massa do fruto.

O conhecimento sobre o manejo da planta do meloeiro, sobretudo no cultivo em ambiente protegido, é de fundamental importância em razão do efeito do raleio e da posição de fixação dos frutos na planta sobre a produtividade e a qualidade dos frutos. Portanto, o trabalho teve como objetivo avaliar características de produtividade e de qualidade de frutos do melão tipo Cantaloupe, cultivar 'Torreon', cultivado em ambiente protegido, variando o número e a posição de fixação dos frutos na planta.

\section{MATERIAL E MÉTODOS}

$\mathrm{O}$ experimento foi desenvolvido em casa de vegetação, no período de 26 de setembro de 2005 a 24 de janeiro de 2006 em Viçosa (MG). A temperatura e a umidade relativa do ar, no interior da casa de vegetação durante o período experimental, foram registradas por termo-higrômetro digital (modelo HT210), colocado à altura do dossel das plantas, com valores médios para temperatura máxima e de mínima de 37,3 e $17,2{ }^{\circ} \mathrm{C}$ e de umidade relativa máxima e mínima de $94,9 \%$ e $39,4 \%$ respectivamente. A casa de vegetação "tipo capela" foi coberta com filme de polietileno de baixa densidade aditivado, de $0,15 \mathrm{~mm}$ de espessura, com fechamento nas frontais e laterais durante a noite e durante parte do dia, quando a temperatura baixava a menos de $20^{\circ} \mathrm{C}$. Utilizou-se o esquema fatorial $2 \times 2$ em blocos ao acaso, retirandose de cada bloco quatro frutos por tratamento, totalizando 20 frutos para análise em cada tratamento. Os tratamentos foram: número de frutos por planta (1 e 2) e de posição de fixação dos frutos 
na planta (entre $5 .^{\circ}$ e $8 .^{\circ}$ nós e entre $15 .^{\circ}$ e $18 .^{\circ}$ nós). O espaçamento adotado foi de $1,0 \times 0,5 \mathrm{~m}$. A parcela útil constou de uma fileira com oito plantas. Utilizouse a cultivar 'Torreon' do grupo Cantalupensis, que possui frutos de casca rendilhada, polpa cor salmão e alto teor de açúcares (TOPSSED, 2007). A semeadura foi realizada em 26/9/2005, em bandejas de poliestireno com 128 células, preenchida com substrato agrícola comercial (Bioplant), e o transplante, feito 22 dias depois, já com a segunda folha expandida nas mudas.

As plantas foram cultivadas em vasos plásticos pretos de $11,5 \mathrm{dm}^{3}$ preenchidos apenas com substrato de fibra de coco Gold Mix tipo 98, contendo uma planta cada um. O substrato, elaborado com casca de coco maduro, corresponde à mistura de $50 \%$ de substrato de textura grosseira e $50 \%$ de substrato de textura granulada, tendo em média, $98 \%$ de matéria orgânica, 95\% de porosidade total, 35\% de capacidade de aeração, $400 \mathrm{~mL} \mathrm{~L}^{-1}$ de capacidade de retenção de água, 0,9 dS m ${ }^{-1}$ de condutividade elétrica e 5,9 de pH.

As adubações de cobertura foram realizadas diariamente, via fertirrigação, com base nas recomendações de Castellane e Araujo (1994) e FURLANI et al. (1999), para macro e micronutrientes, exceto $\mathrm{N}\left(200 \mathrm{mg} \mathrm{dm}^{-3}\right)$ e $\mathrm{P}\left(160 \mathrm{mg} \mathrm{dm}^{-3}\right)$. As irrigações foram realizadas diariamente, por gotejamento, com os emissores espaçados de $0,5 \mathrm{~m} \mathrm{e}$ vazão de $2,3 \mathrm{~L} \mathrm{~h}^{-1}$. Aplicou-se a quantidade de água de 96,3 $\mathrm{L}_{\text {planta }}{ }^{-1}$ no decorrer do ciclo da cultura. $\mathrm{Na}$ fase inicial de crescimento (28 dias) foram aplicados 21,5 L planta ${ }^{-1}$, em quatro aplicações durante o dia; na fase de florescimento e frutificação (60 dias) foram aplicados 70,2 L planta ${ }^{-1}$, em seis irrigações durante o dia e, na fase de colheita (12 dias), foram aplicados 4,6 L planta $^{-1}$ em duas aplicações ao dia. A duração de cada irrigação foi de 5 minutos, a fim de não haver drenagem e perda da solução nutritiva.

As plantas foram mantidas verticalmente, em haste única, com uso de fitilhos fixados na base das plantas e em bambu colocado na horizontal, a $1,80 \mathrm{~m}$ do solo, com a poda da haste principal na $28 .^{a}$ folha. Os frutos, um ou dois por planta, foram fixados nos ramos secundários nas posições previamente estabelecidas realizando-se nesses ramos a poda duas folhas após o fruto fixado. Todas as demais ramificações e frutos foram eliminados. Para auxiliar na polinização, foram colocadas duas colméias de abelhas melíferas na parte externa da casa de vegetação durante o período de floração. Quando necessário, procedeu-se o controle fitossanitário com fungicidas e inseticidas registrados para cultura, aplicando-se a calda no fim da tarde, sobretudo no período da floração e frutificação.
A colheita iniciou-se em 6 de janeiro de 2006, 103 dias após a semeadura, quando se formou nos frutos a camada de abscisão $(50 \%$ a $75 \%$ da circunferência), ponto indicativo da colheita dos frutos nas cultivares desse grupo de meloeiro. Avaliaram-se as seguintes características: massa do fruto; produtividade comercial (consideraram-se comerciais os frutos tipo 3 e 4 - mercado interno e tipo 5 a 8 - mercado externo), firmeza, uniformidade quanto à cor, bom rendilhado de casca, sem deformações, murchamento, rachaduras, danos mecânicos e sinais de podridão e de ataque de insetos; ciclo da cultura, calculado da semeadura até o fim da colheita em cada tratamento; reticulação da casca, atribuindo-se notas de $1(0 \%), 2(25 \%), 3(50 \%), 4(75 \%)$ e $5(100 \%$ da superfície reticulada); espessura da polpa, avaliada na região equatorial, após seccionar o fruto no sentido longitudinal; comprimento e diâmetro de fruto, medidos no sentido longitudinal e transversal do fruto respectivamente; índice de formato, determinado pela razão entre comprimento e diâmetro do fruto; teor de sólidos solúveis e de acidez total titulável, medidas em amostras de fatias de frutos retiradas no sentido longitudinal homogeneizadas em liquidificador para a obtenção do suco.

O teor de sólidos solúveis foi determinado por meio de refratômetro de mesa, modelo ATAGO $3 \mathrm{~T}$, obtendo-se os valores em \%, corrigidos a $20^{\circ} \mathrm{C}$. Para a medida de acidez total titulável, utilizou-se uma alíquota de $10 \mathrm{~mL}$ de suco, em duplicata, à qual foram adicionados $40 \mathrm{~mL}$ de água destilada e três gotas do indicador fenolftaleína alcoólica a 1\% e, em seguida, procedeu-se a titulação com solução de $\mathrm{NaOH} 0,1 \mathrm{~N}$ até o ponto de viragem, com os resultados expressos em \% de ácido cítrico (Instituto ADOLFo Lutz, 1985). O índice de maturação foi determinado por meio da razão sólidos solúveis/acidez total titulável. No suco empregado para a determinação das características anteriores, foram avaliados os teores de açúcares solúveis totais, quantificados por meio da reação com Antrona, conforme YeMm e WiLLIS (1954) e os açúcares redutores, pelo método do DNS (Miller, 1959). Os açúcares não redutores foram determinados por diferença entre a concentração dos açúcares solúveis totais e açúcares redutores.

Os resultados foram submetidos à análise de variância e as médias dos tratamentos comparadas pelo teste de Tukey a $5 \%$ de probabilidade no software SAEG 9.0. Foi feita a correlação de Pearson para a área foliar (determinada por meio da medição em aparelho Li-3000) x massa de frutos, para área foliar $x$ sólidos solúveis, para a massa de frutos $\mathrm{x}$ sólidos solúveis, para massa de frutos $x$ reticulação da casca e entre reticulação da casca $x$ sólidos solúveis. 


\section{RESULTADO E DISCUSSÃO}

Observaram-se efeito significativo do número de frutos por planta sobre a massa do fruto, a reticulação de casca, o comprimento de fruto e o índice de formato, de modo que, plantas mantidas com apenas um fruto comparada a plantas com dois frutos proporcionaram maiores valores para estas características (Figuras 1A, 1D, 1F e 1H). Constatouse efeito significativo da posição de fixação dos frutos na planta e os frutos que se fixaram do $5 .^{\circ}$ ao $8 .^{\circ}$ nós comparados aos advindos do $15 .^{\circ}$ ao $18 .^{\circ}$ nós tiveram menor massa do fruto e ciclo cultural e maior reticulação de casca (Figuras 1A, 1C e 1D). Observouse efeito significativo da interação do número de frutos por planta x posição de fixação dos frutos na planta sobre a espessura da polpa, sobre o diâmetro de frutos e produtividade comercial de frutos (Figuras 1E, 1G e 1B). Quanto à espessura da polpa e ao diâmetro dos frutos, em plantas com apenas um fruto comparado a plantas com dois frutos independentemente da posição de fixação dos frutos na planta, assim como, plantas com apenas um fruto quando fixado entre $15 .^{\circ}$ e $18 .^{\circ}$ nós comparado aos frutos fixados entre $5 .^{\circ}$ e $8 .^{\circ}$ nós constataram-se maior espessura de polpa e diâmetro de frutos (Figuras 1E e 1G). Observou-se maior produtividade comercial em plantas com dois frutos, comparadas a plantas com apenas um fruto quando fixados do $5 .^{\circ}$ ao $8 .^{\circ}$ nós $(27,2 \%)$ e do $15 .^{\circ}$ ao $18 .^{\circ}$ nós $(43,2 \%)$ e, também, quando esses dois frutos foram fixados entre o $15 .^{\circ} \mathrm{e} 18 .^{\circ}$ nós comparado àqueles advindos do $5 .^{\circ}$ e $8 .^{\circ}$ nós com incremento de $24,5 \%$ (Figura 1B). Plantas mantidas com dois frutos tiveram maior produtividade comercial, o que se deve ao maior número de frutos por planta e por área, fato também observado por MonTEIRO e MeXIA(1988) nas cultivares de melão MacDimon e Harvest King quando o número de frutos por planta passou de 1 para 2. Neste trabalho, plantas com dois frutos fixados entre o $15 .^{\circ}$ e $18 .^{\circ}$ nós foram mais produtivas do que quando fixados entre o $5 .^{\circ}$ e $8{ }^{\circ}$ nós. Neste caso, a fixação dos frutos em posições mais elevadas na planta atrasa a competição entre fonte e dreno proporcionando maior crescimento da planta evidenciado pela área foliar e, consequentemente, elevação no fornecimento de assimilados para o crescimento dos frutos (SYN et al., 1991).

Resultados semelhantes foram analisados por MARUYAMA et al. (2000), os quais observaram maior produção em plantas de melão Cantaloupe híbridos Bônus n. ${ }^{\circ} 2$ e D. Carlos cujos frutos foram fixados entre o $12 .^{\circ}$ e $15 .^{\circ}$ nós comparado àquelas com frutos fixados entre o $5 .^{\circ}$ e $8 .^{\circ}$ nós. A maior competição entre órgãos vegetativo e reprodutivo ocorre quando da fixação de frutos próximos à base da planta, comprometendo seu crescimento e, conseqüentemente, a produção total, principalmente, se houver área foliar insuficiente no momento em que os frutos forem fixados (SEABRA JúNIOR et al., 2003).

A condução da planta com apenas um fruto, assim como a fixação de frutos em posições mais elevadas (entre $15 .^{\circ}$ e $18 .^{\circ}$ nós) permitiu maior área foliar disponível por fruto, o que resultou em menor competição por fotossintatos entre órgãos vegetativo e reprodutivo com mais assimilados disponibilizados da fonte (folhas) para o dreno (frutos) e conseqüente aumento da massa do fruto. Esses resultados estão de acordo com os constatados por BARNI et al. (2003), em cultivo protegido com melão Cantaloupe cultivar $\mathrm{Hy}$ Mark e também por VALANTin-Morinson et al. (2006), em melão Charentais cultivar Talma. Esses autores observaram que o aumento do número de frutos por planta proporcionou redução na massa do fruto do meloeiro em função dos fotoassimilados produzidos pela fonte serem divididos para o crescimento dos frutos quando aumenta seu número na planta.

Houve redução do ciclo cultural em 9,4 dias quando da condução de plantas com frutos fixados entre o $5 .^{\circ}$ e $89^{\circ}$ nós comparado àquelas com frutos fixados do $15 .^{\circ}$ e $18 .^{\circ}$ nós (Figura $1 \mathrm{C}$ ) em razão das ramificações laterais emitidas nesta posição terem ocorrido primeiro, em comparação às ramificações que saíram entre o $15 .^{\circ}$ e $18 .^{\circ}$ nós. Essas ramificações são as que emitem as flores hermafroditas; portanto, devese ponderar se a antecipação da colheita está associada à maior produção, qualidade de frutos e preço mais alto dos frutos no momento da colheita, lembrando que a redução do ciclo cultural contribui para a diminuição de gastos com mão-de-obra e insumos (MARTINS et al., 1998).

Nas plantas conduzidas com apenas um fruto e quando esses foram fixados entre o $5 .^{\circ}$ e $80^{\circ}$ nós houve maior reticulação da casca (Figura 1D). Este fato pode ser atribuído à maior disponibilidade de fotoassimilados em vista da redução da competição entre órgãos da planta quando mantidas com apenas um fruto e também à maior força do dreno no início do desenvolvimento da planta em frutos situados entre o $5 .^{\circ}$ e $8 .^{\circ}$ nós.

O rendilhamento do fruto do meloeiro está diretamente relacionado com o aumento da taxa de crescimento de frutos. De acordo com KeREN-KeISERMAN et al. (2004 b), o desenvolvimento do rendilhado no fruto tem sido caracterizado como resposta à rachadura da superfície do fruto, resultado do seu rápido crescimento, pois eleva a tensão de ruptura na casca e promove a presença de rachaduras, que rompem a cutícula, as células da epiderme e as da hipoderme. 
A
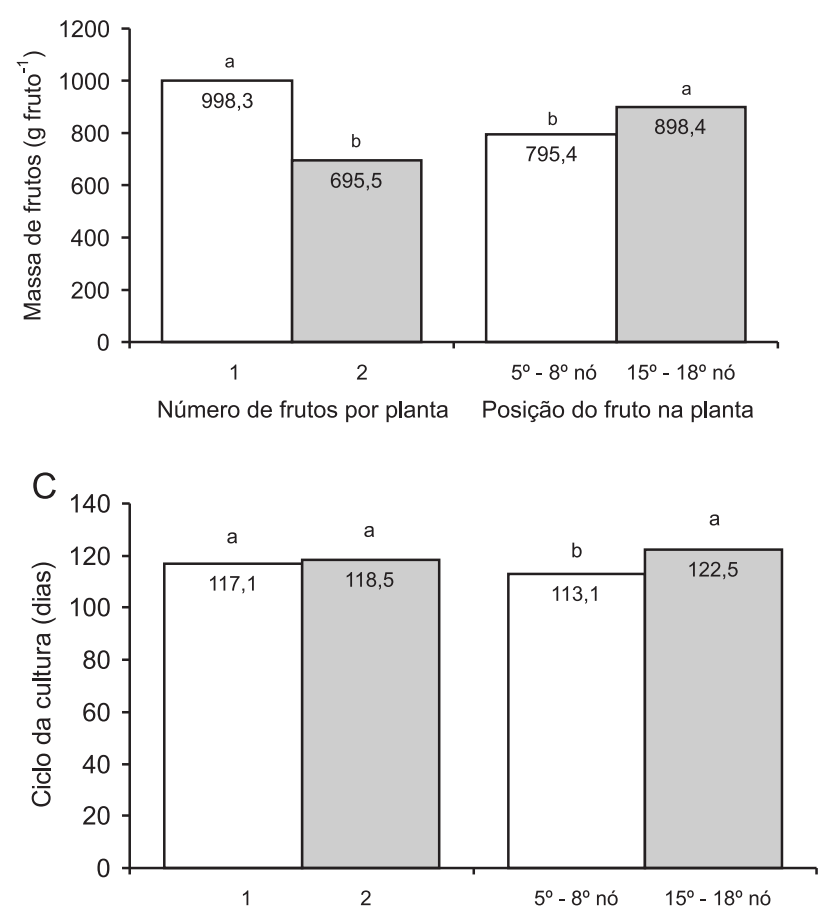

Número de frutos por planta Posição de frutos na planta

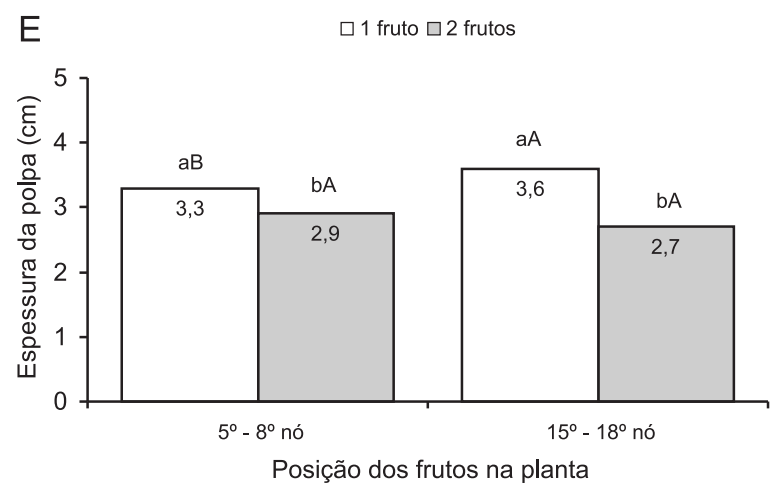

G

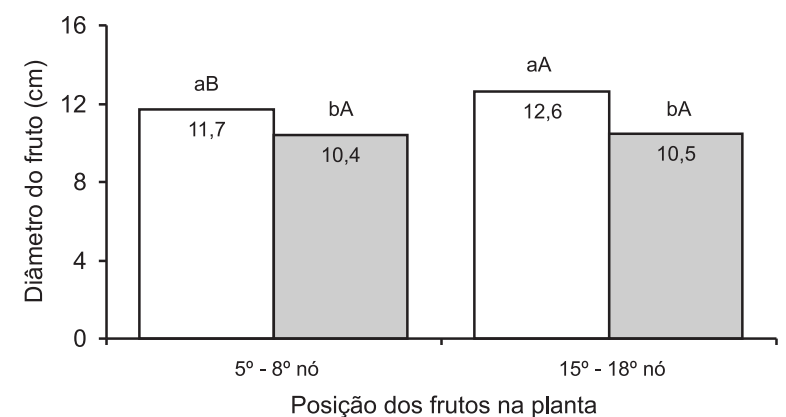

B

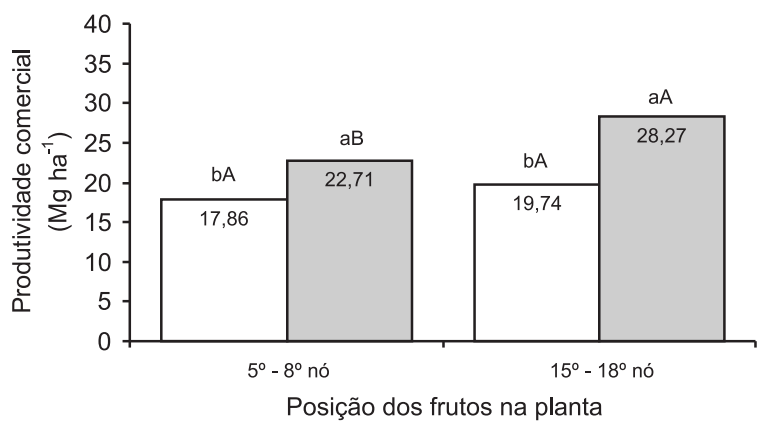

D

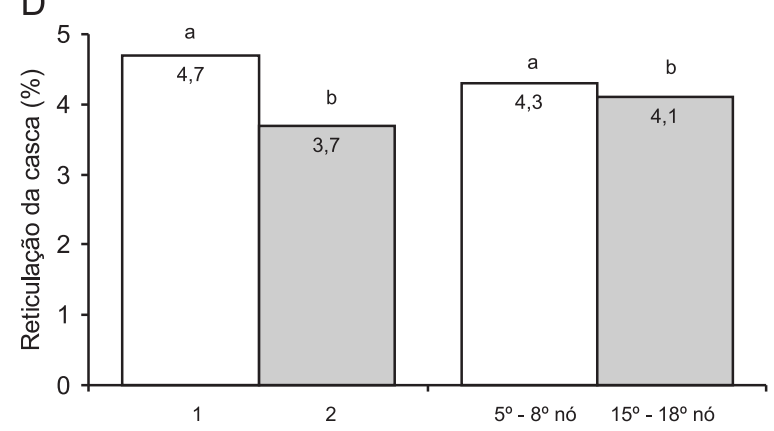

Número de frutos por planta Posição do fruto na planta
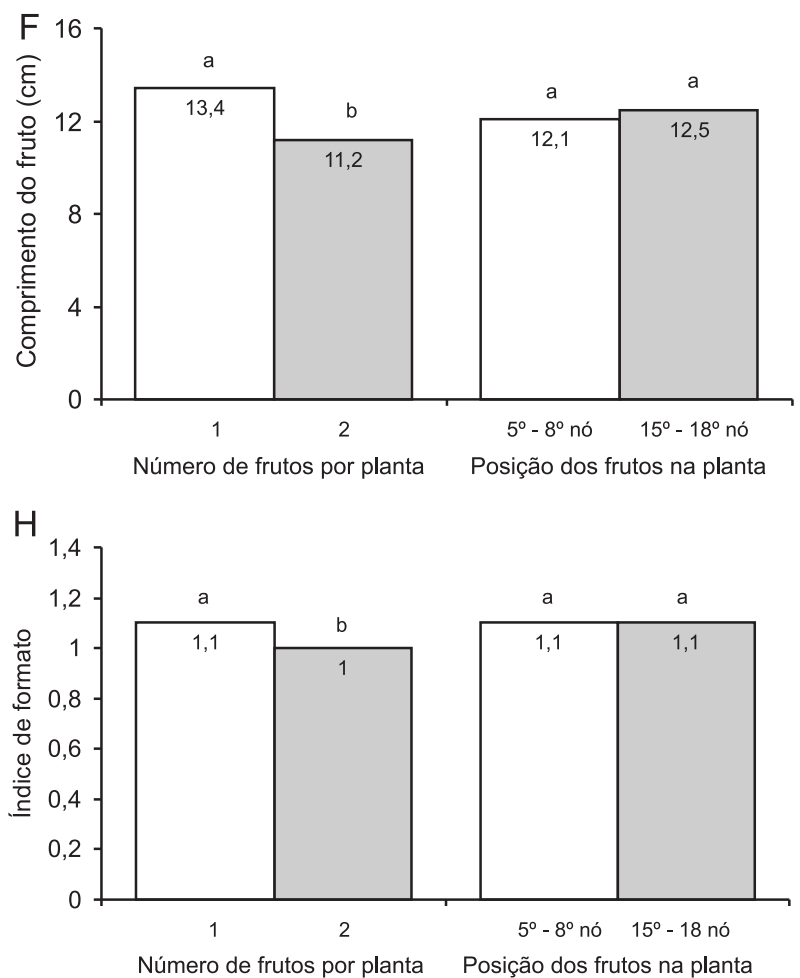

Figura 1. Valores médios de massa dos frutos (A), produtividade comercial (B), ciclo de cultura (C), reticulação da casca (D), espessura da polpa (E), comprimento (F), diâmetro $(G)$ e índice de formato (H) dos frutos de meloeiro 'Torreon' cultivados em ambiente protegido em função do número e da posição de fixação dos frutos na planta.

* Efeito isolado de número de frutos por planta (NFP) e da posição de fixação dos frutos na planta (PFP): médias seguidas pela mesma letra não diferem entre si.

* Na interação NFP x PFP: médias seguidas pela mesma letra minúscula comparam NFP dentro de PFP, e pela mesma letra maiúscula comparam PFP dentro de NFP pelo teste Tukey a $5 \%$ de probabilidade. 
Essas rachaduras aprofundam-se e se alargam, e abaixo delas as células da periderme iniciam a multiplicação, enchendo as rachaduras e produzindo massa de células com paredes suberizadas que se estendem acima da superfície do fruto. Portanto, o rendilhamento do fruto é um dos fatores que determina sua qualidade, pois a suberização fortalece a casca, serve como proteção contra injúria mecânica e, do ponto de vista do consumidor, tem importância estética elevando o valor de mercado (Keren Keiserman et al., 2004 a).

A espessura da polpa constitui atributo de qualidade importante por se tratar da parte comestível do fruto do meloeiro (CoelHo et al., 2003). Assim como para a massa do fruto, verificou-se o aumento da espessura da polpa em frutos de plantas com apenas um fruto comparado a plantas com dois frutos, independentemente da posição de fixação dos frutos na planta (Figura 1E). Em princípio, esse aumento se deve também à diminuição da competição entre fonte e dreno. Resultado semelhante foi obtido por Purquerio e Ceć́lio Filho (2005), no cultivo do melão Cantaloupe híbrido Bônus $n .^{\circ} 2$, em que o aumento do número de frutos por planta de dois para quatro reduziu a espessura da polpa de 3,1 para $2,9 \mathrm{~cm}$. Também, Costa et al. (2004), trabalhando com o híbrido de melão Bônus $n .^{\circ} 2$ observaram que o aumento de dois para quatro frutos por planta reduziu a espessura da polpa de 2,76 para $2,57 \mathrm{~cm}$. Quanto à posição de fixação dos frutos na planta, apenas quando conduzida com um fruto, observouse maior espessura de polpa dos frutos quando fixados entre o $15 .^{\circ}$ e $18 .^{\circ}$ nós, comparados aos frutos do $5 .^{\circ}$ e $8 .^{\circ}$ nós. Neste trabalho, a espessura média da polpa foi de $2,8 \mathrm{~cm}$ independentemente da posição de fixação dos frutos na planta.

Obteve-se também maior comprimento e diâmetro de frutos em plantas com apenas um fruto, independentemente da posição de fixação dos frutos na planta (Figuras 1F e 1G). Esses resultados corroboram os obtidos por FAGAN et al. (2006), que trabalharam com melão Cantaloupe 'Torreon', e constataram que a condução da planta com um fruto, comparada a plantas com dois frutos, proporcionou maior valor para comprimento e diâmetro dos frutos. Segundo esses autores, quando se aumenta a densidade de frutos por planta, a demanda de fotoassimilados pelos frutos se eleva instalando forte competição por fotoassimilados entre eles. Entretanto, o aparecimento de um novo fruto compete mais fortemente com os frutos remanescentes do que com os órgãos vegetativos (VALANTIN et al., 1999), revelando que a força do dreno dos frutos decresce com o aumento do seu número e, dessa forma, limitando o acúmulo de fitomassa no fruto, mesmo com aumento dos frutos fixados. Para Valantin-Morinson et al. (2006), o carregamento do fruto na planta do meloeiro influencia a taxa de crescimento e o tamanho final dos frutos. No meloeiro, Higashy et al. (1999), trabalhando com melão Cantaloupe em cultivo protegido, observaram que a maior causa na diferença do tamanho de frutos das cultivares Fuyu A e Natsu 4 foi decorrente da diferença no número de células do pericarpo. De acordo com esses autores, indica o envolvimento do processo de divisão celular na determinação do tamanho do fruto, embora após cessar a divisão celular, expansão celular possa também estar envolvida. Portanto, nesse trabalho, o menor tamanho de fruto em plantas que fixaram dois frutos, provavelmente, se deve ao menor número de células formadas sob condições de maior competição por assimilados.

O índice de formato do fruto variou apenas em função do número de frutos por planta (Figura 1H). Nas plantas conduzidas com um fruto, comparado a plantas com dois frutos registrou-se maior valor, em razão da maior variação no comprimento em relação ao diâmetro do fruto. Resultados semelhantes foram observados por Granjeiro et al (1999) em híbridos de melão Amarelo Gold Mine e AF646, os quais verificaram que houve tendência dos frutos tornaremse mais redondos à medida que se aumentou o número de frutos por planta. Em melão, o índice de formato é atributo de qualidade importante na classificação e padronização, podendo determinar a aceitação e valorização do produto para determinados mercados. Também define a embalagem e o arranjo dos frutos no seu interior. Portanto, frutos com índice de formato próximo do valor 1 são preferidos, visto que acima (alongados) e abaixo (achatados) deste valor há comprometimento da sua acomodação nas embalagens (Purquerio e Cecílio Filho, 2005).

Foi obtido efeito significativo do número de frutos por planta sobre o teor de sólidos solúveis, sobre o índice de maturação e sobre a concentração de açúcares solúveis totais. Frutos de plantas conduzidas com apenas um fruto, comparados a frutos de plantas com dois, proporcionaram maiores valores para estas características (Figuras 2A, 2C e 2D). Quanto à posição de fixação dos frutos na planta, essa interferiu na acidez total titulável e no índice de maturação, obtendo-se maior acidez total e menor índice de maturação quando os frutos foram fixados entre o $5 .^{\circ}$ e $8 .^{\circ}$ nós (Figuras $2 \mathrm{~B}$ e 2C). Houve efeito significativo também da interação número de frutos por planta $x$ posição de fixação dos frutos na planta sobre os açúcares redutores, cujas plantas com dois frutos obtiveram maior concentração de açúcares redutores quando fixados entre o $5 .^{\circ}$ e $8 .^{\circ}$ nós comparados àqueles advindos do $15 .^{\circ}$ e $18 .^{\circ}$ nós, e maior concentração de açúcares não redutores somente quando fixado entre o $5 .^{\circ}$ e $8 .^{\circ}$ nós. 
A
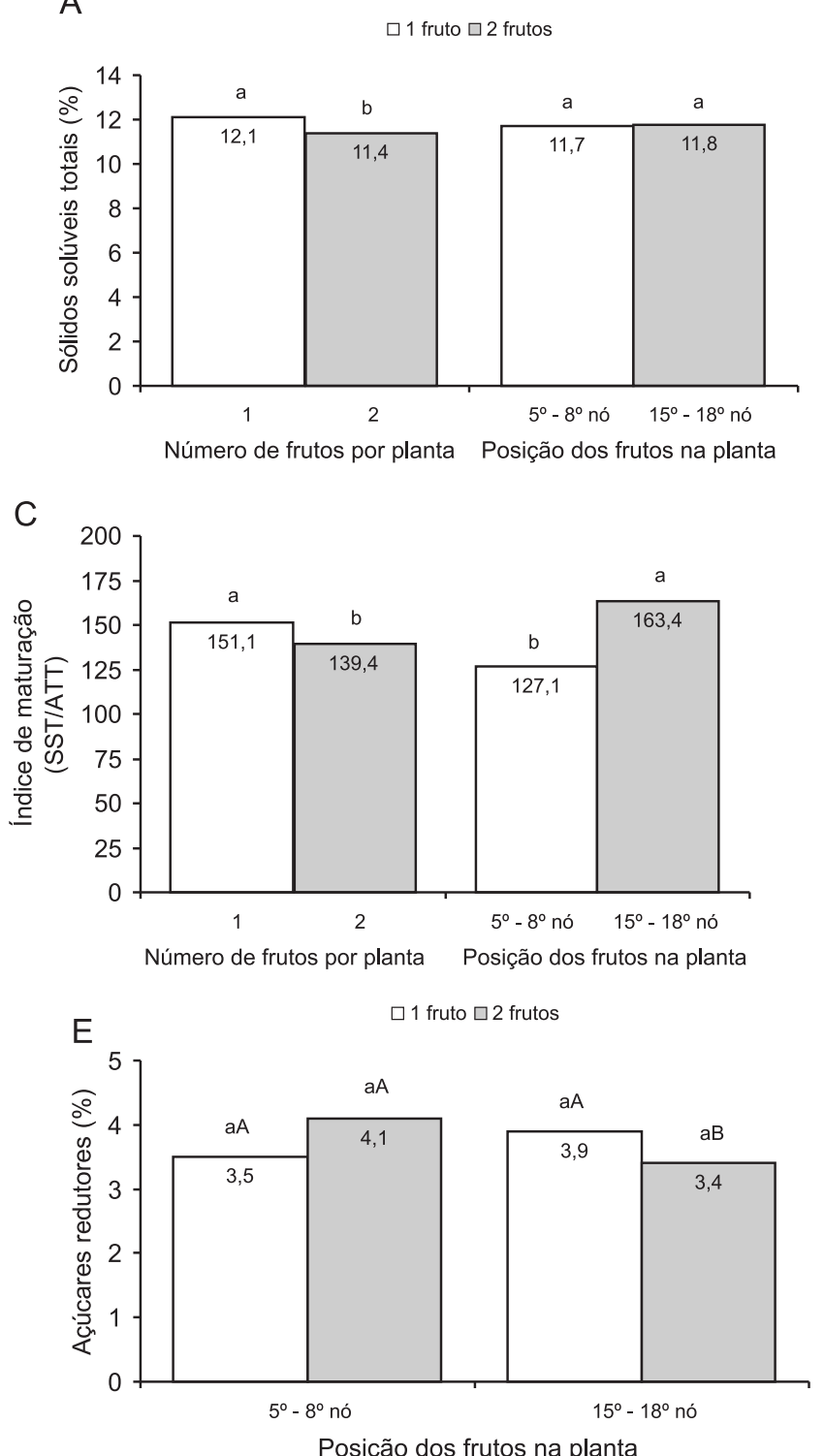
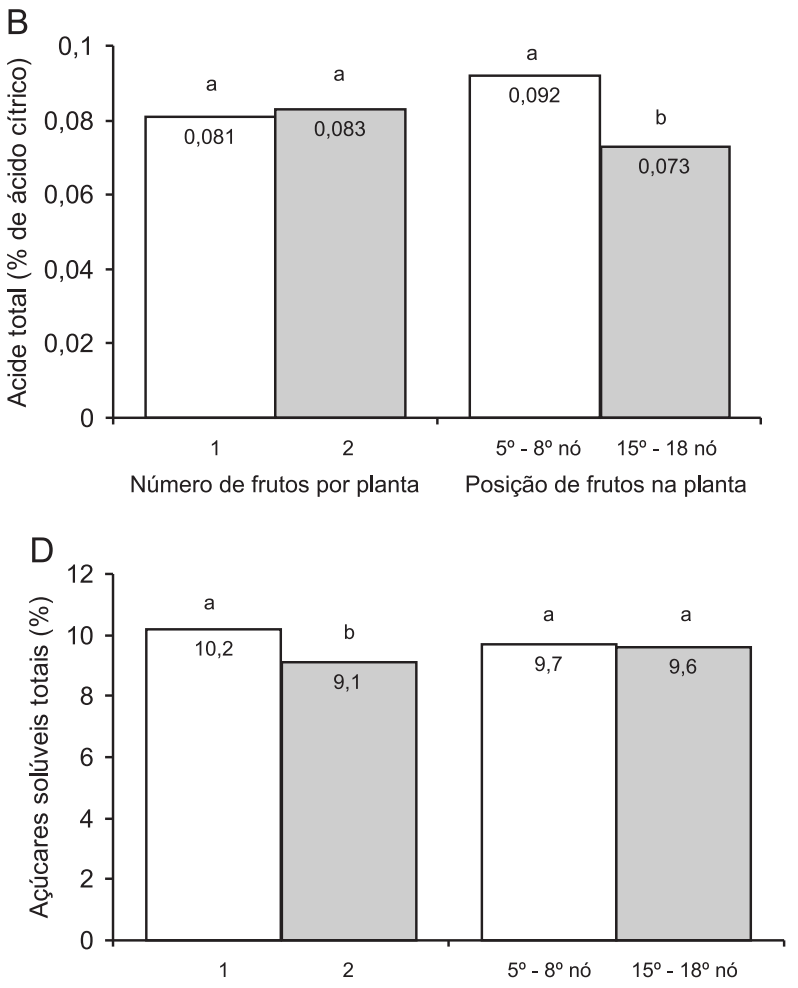

Número de frutos por planta Posição dos frutos na planta
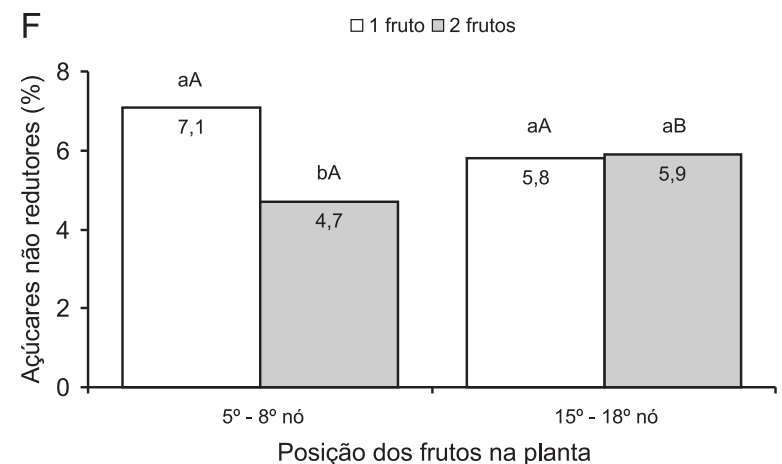

Figura 2. Valores médios de sólidos solúveis (A), acidez total titulável (B), índice de maturação (C), açúcares solúveis totais (D), açúcares redutores (E) e não redutores (F) de frutos de meloeiro 'Torreon' cultivados em ambiente protegido em função do número e da posição de fixação dos frutos na planta.

* Efeito isolado de número de frutos por planta (NFP) e posição de fixação dos frutos na planta (PFP): médias seguidas pela mesma letra não diferem entre si.

* Na interação NFP x PFP: médias seguidas pela mesma letra minúscula comparam NFP dentro de PFP, e pela mesma letra maiúscula comparam PFP dentro de NFP pelo teste Tukey a $5 \%$ de probabilidade.

Neste caso, plantas com apenas um fruto registraram maior valor comparado a plantas que continham dois frutos (Figuras 2E e 2F). O maior teor de sólidos solúveis observado em plantas conduzidas com apenas um fruto pode ser atribuído à maior disponibilidade de área foliar por fruto, que aumenta o aporte de fotoassimilados para os frutos, conforme verificado por VALANTIN-Morinson et al. (2006), em melão Cantaloupe cultivar Talma. Esses autores observaram a redução no teor de sólidos solúveis no melão devido à maior competição por assimilados quando a planta foi conduzida com dois frutos comparada a plantas com apenas um fruto, e também por LoNG et al. (2004) em melão Cantaloupe cultivar Malibu. Neste caso, observaram-se valores de 9,0\% e 7,8\% no teor de sólidos solúveis em frutos quando as plantas foram conduzidas com um e dois frutos respectivamente. $\mathrm{O}$ teor de sólidos solúveis em frutos do meloeiro é influenciado pela fonte e pela demanda do dreno; o conteúdo de açúcares está diretamente relacionado com teor de sólidos solúveis e constitui-se em bom indicador do "adoçamento", decorrente principalmente da sacarose (Long et al., 2004). 
Não foi verificada diferença significativa no teor de sólidos solúveis em vista da posição de fixação dos frutos na planta, no entanto, existem resultados contrastantes na literatura. Em melões Cantaloupe híbridos Bônus n. ${ }^{\circ} 2$ e D. Carlos, MaruYama et al. (2000) observaram o mesmo comportamento deste trabalho quanto ao teor de sólidos solúveis quando os frutos foram conduzidos entre o $5^{0}$ e $8^{0}$ nós, $9^{0} \mathrm{e}$ $11^{0}$ nós e $12^{0}$ e $15^{0}$ nós. Por outro lado, SYN et al. (1991) encontraram maior teor de sólidos solúveis em melões 'House-Euncheon' fixados do $8 .^{\circ}$ ao $10 .^{\circ}$ nós em relação a posições do $4 .^{\circ}$ ao $6 .^{\circ}$ nós e do $6 .^{\circ}$ ao $8 .^{\circ}$ nós. Não observaram, porém, diferença significativa para híbrido Keumssaragi, nas várias faixas de fixação testadas. Esses resultados divergentes podem ser atribuídos às cultivares utilizadas, práticas de manejo das plantas, diferenças entre condições edafoclimáticas e incidência de doenças e de pragas. Essas variáveis podem interferir na taxa de crescimento das plantas, na área foliar fotossintética ativa e influenciar na produção de fotossintatos, no crescimento e acúmulo de açúcares nos frutos.

A acidez total titulável foi maior no extrato da polpa dos frutos fixados entre o $5 .^{\circ}$ e $8 .^{\circ}$ nós comparado aos frutos entre o $15 .^{\circ}$ e $18 .^{\circ}$ nós. Nos frutos, de maneira geral, a acidez total representa um dos componentes do flavor. Os valores verificados para a acidez total neste trabalho estão de acordo com as quantidades de ácido cítrico observados em melões, que variam de 0,05 a $0,35 \mathrm{~g}$ do ácido cítrico por 100 $\mathrm{mL}$ de suco (Costa et al., 2004). No melão, WANG et al. (1996) obtiveram valor maior do que o obtido neste trabalho com máximo de $0,12 \%$ de ácido cítrico para a cultivar Mackdimon; todavia, segundo esses autores, em razão da baixa concentração no extrato da polpa dos frutos, a intervenção da acidez no sabor e aroma de frutos do meloeiro não é muito representativa.

O maior índice de maturação obtido em plantas conduzidas com apenas um fruto foi devido ao incremento no teor de sólidos solúveis já que a acidez total não variou entre plantas mantidas com um ou dois frutos (Figura 2C). Por outro lado, o maior índice de maturação obtido em frutos fixados entre o $15 .^{\circ}$ e $18 .^{\circ}$ nós foi devido à menor acidez total no extrato da polpa desses frutos quando fixados em posições mais elevadas na planta, visto que o teor de sólidos solúveis não diferiu. Costa et al. (2004) não obtiveram alterações no índice de maturação com o aumento do número de frutos por planta de dois para quatro, pela pouca variação tanto na acidez total quanto no teor de sólidos solúveis. Segundo Villanueva et al. (2004), modificações no sabor de melão são decorrentes de alterações nos compostos aromáticos, ácidos orgânicos e açúcares solúveis.
Estes autores observaram que o incremento no teor de sólidos solúveis do fruto do meloeiro em estágio mais avançado de maturação proporcionou elevação desta relação, sendo os valores influenciados pelo crescimento do fruto.

Os principais açúcares presentes em melão são a glicose e frutose (açúcares redutores) e a sacarose. Neste trabalho, a participação dos açúcares solúveis totais nos sólidos solúveis no momento da colheita, foi de $84,3 \%$ e $79,8 \%$, para plantas com um e dois frutos, e de $82,3 \%$ e $81,4 \%$, respectivamente, para frutos fixados entre o $5 .^{\circ}$ e $8 .^{\circ}$ nós e $15 .^{\circ}$ e $18 .^{\circ}$ nós. Independentemente da posição de fixação dos frutos na planta, a contribuição dos açúcares redutores e não redutores foi de $36,6 \%$ e $63,4 \%$ em plantas com apenas um fruto e de $41,6 \%$ e $58,4 \%$ em plantas com dois frutos. Portanto, plantas com um fruto proporcionaram frutos com maior concentração de açúcares solúveis totais e quando esse fruto foi fixado entre o $5 .^{\circ}$ e $8 .^{\circ}$ nós, houve maior concentração de açúcares não redutores, evidenciando a importância da fonte (área foliar) disponível por fruto. Para HUBBAR et al. (1990), o metabolismo da sacarose no amadurecimento de melão Cantaloupe é influenciado pela área foliar. Estes autores observaram menor concentração final de sacarose em frutos de meloeiro com a redução da área foliar por fruto. Assim, o suprimento continuado de assimilados é necessário para que a síntese e acumulação de sacarose possam ocorrer. Esse processo implica que frutos como o melão, que não têm amido como carboidrato de reserva, devem ser mantidos nas plantas até a maturação completa para assegurar adequada qualidade na colheita.

Observou-se efeito positivo e significativo para todas as características submetidas à análise de correlação (Tabela 1). A área foliar da planta representa importante papel na produtividade e qualidade de frutos do meloeiro. A redução do número de frutos por planta permitiu maior massa do fruto e de teor de sólidos solúveis, em virtude da elevação da área foliar disponível por fruto contribuir para a maior produção de fotossintatos a ele direcionados. MonTEIRO e MexiA (1988) observaram diferença entre cultivares de meloeiro para a correlação área foliar por fruto $x$ massa do fruto, com a cultivar MacDimon, no valor de 0,87 comparado a Harvest King que foi de 0,62. Observaram também diferença para a correlação área por fruto $\mathrm{x}$ teor de sólidos solúveis com valores iguais a 0,67 e 0,77 para MacDimon e Harvest King respectivamente. Neste trabalho, foi obtida correlação significativa entre massa do fruto $\mathrm{x}$ teor de sólidos solúveis de 0,68. De acordo Monteiro e Mexia (1988), frutos maiores têm poder de dreno mais que proporcional ao seu aumento de peso, principalmente, na ausência de competição. O efeito positivo da correlação da reticulação da casca x massa do fruto e 
teor de sólidos solúveis foi devido à maior área foliar disponível por fruto que permitiu maior crescimento e acúmulo dos sólidos solúveis. Nestas condições, o rápido crescimento do fruto favorece seu rendilhamento, conforme KEREN-KEISERMAN et al. (2004 b).

Tabela 1. Coeficientes de correlação de Pearson entre área foliar por fruto, massa média do fruto, teor de sólidos solúveis e reticulação da casca de frutos do meloeiro 'Torreon'. Viçosa (MG), UFV, 2006

\begin{tabular}{lc}
\hline Correlações & Valor \\
\hline $\begin{array}{l}\text { Área foliar por fruto x massa do fruto } \\
\text { Área foliar por fruto x teor de sólidos } \\
\text { solúveis totais }\end{array}$ & $0,8105^{* *}$ \\
$\begin{array}{l}\text { Massa do fruto x teor de sólidos } \\
\text { solúveis totais }\end{array}$ & $0,6849^{* *}$ \\
$\begin{array}{l}\text { Massa do fruto x reticulação da casca } \\
\text { Reticulação da casca x teor de sólidos } \\
\text { solúveis totais }\end{array}$ & $0,7268^{* *}$ \\
\hline
\end{tabular}

\section{CONCLUSÕES}

1. A produção e a qualidade de frutos do meloeiro 'Torreon' são alteradas ao variar o número de frutos e posição de fixação desses frutos na planta.

2. A diminuição do número de frutos por planta, de dois para um, melhora sua qualidade, conforme revelam a reticulação da casca, a espessura da polpa, os sólidos solúveis, a massa do fruto, açúcares não redutores e totais; além disso, elevam o comprimento, índice de formato e índice de maturação, todavia reduz a produtividade comercial, independentemente da posição de fixação dos frutos na planta.

3. O atraso na frutificação, com frutos fixados entre o $15 .^{\circ}$ e $18 .^{\circ}$ nós, reduz a reticulação da casca e a acidez total, no entanto, eleva o ciclo da cultura, o índice de maturação, a massa do fruto e a produtividade, comparado aos frutos advindos do $5 .^{\circ}$ e $8 .^{\circ}$ nós.

4. Correlacionam-se positivamente: a massa do fruto e o teor de sólidos solúveis com área foliar por fruto; a massa do fruto com o teor de sólidos solúveis e com a reticulação da casca e a reticulação de casca com o teor de sólidos solúveis.

\section{REFERÊNCIAS}

BARNI, V.; BARNI, N.A.; SILVEIRA, J.R.P. Meloeiro em estufa: duas hastes é o melhor sistema de condução. Ciência Rural, Santa Maria, v.33, n.6, p.1039-1043, 2003.
CASTELLANE, P.D.; ARAUJO, J.A.C. Cultivo sem solo: hidroponia. Jaboticabal. FUNEP, 1994. 43p.

COELHO, E.V.; FONTES, P.C.R.; CARDOSO, A.A. Qualidade do fruto de melão rendilhado em função de doses de nitrogênio. Bragantia, Campinas, v.62, n.2, p.173-178, 2003.

COSTA, C.C.; CECÍLIO FILHO, A.B.; CAVARIANI, R.L.; BARBOSA, J.C. Concentração de potássio na solução nutritiva e a qualidade e o número de frutos de melão por planta em hidroponia. Ciência Rural, Santa Maria, v.34, n.3, p.731-736, 2004.

EL-KEBLAWY, A.; LOVETT-DOUST, J. Resources re-allocation following fruit removal in cucurbits, patterns in cantaloupe melon. New Phytologist, Cambridge, v.134, n.3, p.413-422, 1996.

FAGAN, EB; MEDEIROS, SLP; SIMON, J; LUZ, GL; BORCIONI, E; JASNIEWICZ, LR; CASAROLI, D; MAFRON, PA. Evolução e partição de massa seca do meloeiro em hidroponia. Acta Siencia Agronomy, Maringá, v.28, n.2, p. 165-172, 2006.

FURLANI, P.R.; SILVEIRA, L.C.P.; BOLONHEZI, D.; FAQUIN, V. Cultivo hidropônico de plantas. Campinas: IAC, 1999. 52p. (Boletim Técnico 180)

GRANJEIRO, L.C.; PEDROSA, J.F.BEZERRA NETO, F.; NEGREIROS, M.Z. Qualidade de híbridos de melão amarelo em diferentes densidades de plantio. Horticultura Brasileira, Brasília, v.17, n.2, p. 110-113, 1999.

HIGASHI K; HOSOYA K; EZURA H. Histological analysis of fruit development between two melon (Cucumis melo L. reticulatus) genotypes setting a different size of fruit. Journal of Experimental Botany, Alexandria, v.50, n.339, p. 1593-1597, 1999.

HUBBARD, N.L.; PHARR, D.M. Sucrose metabolism in ripening muskmelon fruit as affected by leaf area. Journal American Society for Horticultural Science, Alexandria, v.115, n.5, p.798-802, 1990.

IBGE. Instituto Brasileiro de Geografia e Estatística. 2007. 6 de janeiro. Indicadores conjunturais - produção agrícola/ agricultura. Disponível em http://www.ibge.gov.br/

INSTITUTO ADOLFO LUTZ. Normas analíticas, métodos químicos físicos para análise de alimentos. 3.ed. São Paulo: IAL, $1985.533 \mathrm{p}$.

KEREN-KEISERMAM A; TANAMI Z;SHOSEYOO;GINZBERG I. Peroxidade activityassociated with suberization process of the muskmelon (Cucumis melo L.) rind. Physiologia Plantarum, Ashford, v.121, n.2, p. 141-148, 2004 a.

KEREN KEISERMAM, A.; TANAMI, Z.; SHOSEYO, O.; GINZBERG. I. Differing rind characteristic of developing fruit of smooth and netted melons. Journal of Horticulural Science \& Biotechonoly, Ashford, v.79, n.1, p.107-113, 2004 b.

LONG, R.L.; WALSH, K.B.; ROGERS, G.; MIDMORE, D.J. Source-sink manipulation to increase melon (Cucumis melo L.) fruit biomass and soluble sugar content. Australian Journal of Agricultural Research, Victoria, v.55, n.7, p. 12411251, 2004. 
MARTINS, S.R.; PEIL, R.M.; SCHWENGBER, J.E.; ASSIS, F.N.; MENDEZ, M.E.G. Produção de melão em função de diferentes sistemas de condução de plantas em ambiente protegido. Horticultura Brasileira, Brasília, v.16, n.1, p.24-30, 1998.

MARUYAMA, W.I.; BRAZ, L.T.; CECÍLIO FILHO, A.B. Condução de melão rendilhado sob cultivo protegido. Horticultura Brasileira, Brasília, v.18, n.3, p.175-179, 2000.

MILLER, G.L. Use of dinitrosalicylic acid reagent for determination reducing sugars. Analytical Chemistry, Washington, v.31, n.3, p.426-428, 1959.

MONTEIRO, A.A.; MEXIA, J.T. Influência da poda e do número de frutos por planta na qualidade dos frutos e produtividade do melão. Horticultura Brasileira, Brasília, v.6, n.1, p.9-12, 1988.

PURQUERIO, L.F.V.; CECÍLIO FILHO, A.B. Concentração de nitrogênio na solução nutritiva e número de frutos sobre a qualidade de frutos de melão. Horticultura Brasileira, Brasília, v.23, n.3, p.831-836, 2005.

SEABRA JÚNIOR, S.; PANTANO, S.C.; HIDALGO, A.F.; RANGEL, M.G.; CARDOSO, A.I.I. Avaliação do número e posição do fruto de melancia produzido em ambiente protegido. Horticultura Brasileira, Brasília, v. 21, n. 4, p. 708-711, 2003.

SYN, G.Y.; HEONG, C.S.; YOO, K.C. Effect of temperature, light intensity and fruit setting position on sugar accumulation and fermentation in oriental melon. Journal of Korean Society for Horticultural Science, Gyeongi-do, v.32, n.4, p.440-446, 1991.

TOPSEED AGRISTAR. Nova geração de híbridos. 16 de setembro. 2007. Disponível em http://www.agristar.com.br/.

VALANTIN M.; GARY C.; VAISSIERE B.E.; TCHAMITCHIAN M.; BRUNELI B. Changing sink demand affects the area but not the specific activity of assimilate sources in cantaloupe. Annals of Botany, London, v. 82, n.6, p.711-719, 1998.

VALANTIN M; GARY C; VAISSIÉRE BE; FROSSARD JS. Effect of load fruit on partitioning of dry matter and energy in cantaloupe (Cucumis melo L.). Annals of Botany, London, v.84, n.2, p. 173-181, 1999.

VALANTIN MORINSON, M.; VAISSIERE, B.E.; GARY, C.; ROBIN, P. Source-sink balance affects reproductive development and fruit quality in cantaloupe melon (Cucumis melo L.). Journal of Horticultural Science \& Biotechnology, Ashford, v.81, n. 1, p. 105-117, 2006.

VILLANUEVA, M.J.; TENORIO, M.D.; ESTEBAN, M.A.; MENDONZA, M.C. Compositional changes during ripening of two cultivars of muskmelon fruits. Food Chemistry, London, v.87, n.2, p.179 - 185, 2004.

WANG, Y.; WYLLE, S.G.; LEACH, D.N. Chemical changes during the development and ripening of the fruit of Cucumis melo (Cv. Makdimon). Journal Agricultural Food Chemistry, Washington, v.44, n.1, p.210-216, 1996.

YEMN, E.W.; WILLIS, A.J. The estimation of carbohydrate in plant extracts by anthrote. The Biochemical Journal, London, v.57, n.3, p.505-514, 1954. 